\title{
Roles for Agent Assistants in Field Science: Understanding Personal Projects and Collaboration
}

\author{
William J. Clancey
}

\begin{abstract}
A human-centered approach to computer systems design involves reframing analysis in terms of the people interacting with each other. The primary concern is not how people can interact with computers, but how shall we design work systems (facilities, tools, roles, and procedures) to help people pursue their personal projects, as they work independently and collaboratively? Two case studies provide empirical requirements. First, an analysis of astronaut interactions with CapCom on Earth during one traverse of Apollo 17 shows what kind of information was conveyed and what might be automated today. A variety of agent and robotic technologies are proposed that deal with recurrent problems in communication and coordination during the analyzed traverse. Second, an analysis of biologists and a geologist working at Haughton Crater in the High Canadian Arctic reveals how work interactions between people involve independent personal projects, sensitively coordinated for mutual benefit. In both cases, an agent or robotic system's role would be to assist people, rather than collaborating, because today's computer systems lack the identity and purpose that consciousness provides.
\end{abstract}

Index Terms-Collaborative work, robots, model-based systems, field science, assistants, consciousness

\section{INTRODUCTION: SORTING OUT "HUMAN-ROBOT INTERACTION"}

A nyone looking back over the past few decades must be impressed at what we have accomplished in bringing computer systems to real-world, complex environments-even to imagine assisting astronauts on Mars. In large part, our success is enabled by smaller, cheaper, and more reliable and networked personal computers. That we can imagine networking-with components off-the-shelf-a half-dozen or more supercomputer laptops running on robots, vehicles, and backpacks, distributed over many kilometers [1] is truly astounding from the perspective of those who struggled with punch cards and line printers to develop Artificial Intelligence (AI) programs in the $1970 \mathrm{~s}$.

But with this technology bonus, the tables are turned. The

Manuscript received January 24, 2003. This work was supported in part by the NASA's Computing, Communications, and Information Technology Program, Intelligent Systems subprogram, Human-Centered Computing element, managed by Mike Shafto.

William $J$. Clancey is with the NASA-Ames Research Center, Computational Sciences Division, MS 269-3, Moffett Field, CA 94035 USA on leave from the Institute for Human and Machine Cognition, University of West Florida, Pensacola, FL (phone: 650-604-2526; fax: 650-604-4036; email: william.j.clancey@ nasa.gov) burden is no longer to just show that the computer can do something human-like, such as converse in a dialogue or move down a corridor. Today we must confront the reality of the environments in which we seek to do practical work. The question then becomes, how can computers help people or perhaps more precisely, what help do people need? This question is inherently empirical, though the answers will be determined by how new technologies change the work situation, as total work systems are developed in the context of use [2].

However, there is much confusion about differences between people and machinery and how to properly begin a design study. The rhetoric of "collaboration" and "humanrobot interaction" has disguised for many researchers what they are trying to do and even their own nature as people. For example, a colleague recently developed an on-line ontology to be used for assisting scientists. The database lists under "All Persons" two entities, Robotic Agent and Person. The idea of categorizing software the same as a human being is at the very least sloppy, and at the worst provides a foundation that will muddle and distort every aspect of the system's design.

As another example, a recent AI symposium has been titled, "Human Interaction with Autonomous Systems in Complex Environments." The perspective developed in this article suggests that we deliberately reverse the ordering: Agent interactions with human systems. The system is not a technology that must interact with people, but the whole combination of people, their tools, and the environment. The symposium abstract states:

Autonomy changes the nature of human tasks and can introduce new risks. Mitigating those risks raises issues in autonomous systems research such as: 1) How to accept task inputs from humans; 2) How to adjust the level of autonomy and/or change the distribution of roles and responsibilities between autonomous systems and humans; 3 ) How to model humans and their tasks and to what level of detail and; 4) How to facilitate human understanding of the goals, tasks and contexts of autonomous systems....

These problems are real enough, but perhaps especially serious if the autonomous system is given, as something that must be mitigated. The abstract's proposed solutions-accepting inputs, adjusting the roles, modeling people, and facilitating understanding-fit the traditional view of technical design: From idealized functions (i.e., a 
superhuman teammate) develop technology, adjust the technology to be more usable, and then train people to cope with the resulting difficulties.

A human-centered approach [3] starts instead with the people in their work environment. The science of human interaction-as perceptual-motor, cognitive, and social phenomena-becomes the foundation of work system design, including organizations, facilities, tools, procedures. This perspective reframes the problem. To paraphrase the symposium's abstract:

Organizations, facilities, tools, and formal procedures change the nature of human activity and can introduce new opportunities for action. Realizing the advantages raises issues in work systems design research such as: 1) How to determine how people will do their work in complex environments that do not yet exist; 2) How people will communicate with and learn from each other; 3) How people will exchange roles and responsibilities with each other over time; 4) How tools can facilitate routine tasks, as well as action in dangerous, unexpected situations; 5) How to model a work system, including people, facilities, geography, tools, and procedures and to what level of detail; and 6) How to facilitate human understanding of the operational capabilities and shortcomings of autonomous systems....

The original perspective of the symposium's abstract is not wrong, but it is one-sided. It appears to put the burden on fixing the tools or fixing the people, rather than grounding the original objectives in a better understanding of how people work together and how to facilitate their collaboration. Consider trying to help carpenters by only asking, "How do hammers change the nature of carpentry?" My interest in this article is especially to understand the difference between collaboration and assistance provided by tools. I shall argue that without consciousness, a robot can only assist people and not participate in their collaboration, a role restricted to persons (i.e., agents with a conscious self).

The analysis and models required are not only cognitive, but social and perceptual-motor [4]. In Brahms [5], [6], we have worked for a decade to provide such a modeling framework, in which computer systems (whether databases or robots) are described and simulated side-by-side with models of groups of people and their activities, within a modeled geography including buildings, tables, etc. and other tools, such as sample bags. Furthermore, we have shown through a series of models that it is advantageous to model a series of full days in order to understand how work actions (down to the task level) are affected by the context of everyday life [7].

For the case of assisting astronauts exploring a planetary surface, we have the good fortune of having fully documented. lunar traverses, transcribed with photographs and digitized video. The six Apollo explorations are a gold mine of data. In this article I analyze a particular Extra-Vehicular Activity (EVA), a traverse (walk and drive) during Apollo 17, to show what data is available and what we can learn about collaboration and assistance. As a second case study, I then examine in more detail the nature of collaboration, analyzing videos of biologists and geologists doing field science on Devon Island, in the High Canadian Arctic. I conclude with a broader philosophic discussion of how to frame the problem of designing tools for scientific field work.

\section{APOLLO 17 DATA AND ANALYSIS SUMMARY}

During the 75 hours on the Moon, the Apollo 17 crew conducted three EVAs totaling 22 hours on the lunar surface. These EVAs included lunar rover traverses totaling $36 \mathrm{~km}$, collection of lunar samples at 22 locations in the Taurus-Littrow Valley, deployment or performance of 10 science experiments, and examination and photography of the lunar surface. [8]

\section{A. Objective and Method}

This case study is motivated by a problem and : an opportunity. The problem is that the accomplishments of the Apollo $17 \mathrm{crew}$ during their three days on the moon could not be sustained for weeks at a time, let alone months on Mars. The pace was too fast; the amount of work and difficulties in navigating and using tools too strenuous. Furthermore, the assistance provided by CapCom ${ }^{1}$ that made the work efficient at all will be unavailable from Earth during Mars surface operations due to the 10-40 minute roundtrip time delay.

The opportunity arises from the observation that CapCom provided many services that could be easily automated:

146:30:19 Cernan: Say, Bob, where can I get a new set of bags?

146:30:23Parker: Okay, you want new bags...They'll be under Jack's seat.

Automating the CapCom role would not only make a Mars mission possible, but also make the work less burdensome than it was on the moon, because many of the verbal interactions with the crew would be replaced by telemetry.

Furthermore, CapCom provides a model of a disembodied agent (not a robot), whose coordination role is distinctly different from the surface crew. He does not work on the same tasks; he does not carry out any physical work. Past research emphasis on computers as robots has almost totally missed the opportunity to develop software agents [9], [10] for assisting in surface exploration. Analysis shows that an agent need not be a collaborator, but an assistant that logs, tracks, advises, and monitors the work. Obviously, the functions of a physical robot and software agents could be combined. But first we need to understand what services people provide when playing this assistant role from a distance.

To reveal the function of CapCom, I categorized and analyzed examples from Apollo 17 of the interaction between the surface EVA crew (Schmitt and Cernan) and CapCom on Earth (Bob Parker). This analysis is based on three segments of the second EVA during Apollo 17, termed "Orange Soil," "Traverse to Station 5," and "Geology Station 5 at Camelot Crater" in the Apollo Lunar Surface Journal (ALSJ [8]). Mission elapsed time is continuous from 145:23:48 to 146:56:34 (about 1.5 hrs). The excerpts were selected to identify the kinds of assistance provided by CapCom. The

\footnotetext{
${ }^{1}$ CapCorn was an astronaut in Mission Control in Houston, who served as the crew members' single point of contact during the mission.
} 
transcript was printed and annotated with written marks, then reformatted as shown here.

Analysis of the transcript reveals the following broad categories of information flow and work management functions as the EVA crew interacts with CapCom throughout their work:

1. Reading out information (logging):

- sample bag numbers

- camera frame counts

- rover systems indicators

2. Asking where materials (cans, bags) are located

3. Providing descriptions (geological, equipment condition) for the record

4. Suggesting, requesting, or documenting equipment settings and usage (e.g., suit cooling, film magazine change, dusting radiators)

CapCom actively manages the work on the lunar surface:

1. Indicates elapsed time, time remaining at a site, including walkback (turn around) warnings

2. States revised plans for substituting, skipping, or reprioritizing work

3. Provides navigation advice, including identifying craters the crew is seeing

These interactions occur in ordinary conversations, with many complications involving disruptive, misheard, and mistaken remarks. The functions and problems are explained further with transcript excerpts, followed by a discussion of broad technological approaches for dealing with the problems.

\section{B. Crew-CapCom Interactions Apollo 17 EVA 2}

This section illustrates all of the identified functions of CapCom (Bob Parker), including information provided to and received from the crew (Gene Cernan and Jack Schmitt), as well as work management (navigation, scheduling, and prioritization). Each functional category is indicated by a subsection heading. For example, the first category indicates that the crew verbally provides bag numbers for rock samples, which CapCom records. Excerpts are sequential (mission elapsed time) within each category. Statements in brackets [...] are comments in the original transcript.

1) Crew: Logging sample bag numbers

Bag information includes source of sample and description. Bob usually responds "Copy that."

145:34:53 Cernan: Bob, the gray material that's adjacent to the red material is in - what would I say - (bag) 510 .

145:35:01 Parker: Copy that.

Bob confirms that he has heard correctly

145:48:21 Parker: Okay, and, Jack, I copied - aside from three trench samples - I copied one single bag of basalt samples. Is that correct?

145:48:35 Schmitt: That's right. 512.

145:48:36 Parker: Copy that.

The crew often works together to take and secure a sample, so descriptions may come from either of them. Here Gene describes Jack's soil sample (465). Bob anticipates the bag number for the rock sample (466). Then Jack changes the topic back to the previous sample (465) to add information. 146:45:37 Schmitt: (Pouring) I think we better leave it at that. 146:45:43 Ceman: Okay, 465. Pick that other one up and I'll bag it real quick.

146:45:45 Parker: Copy that.
146:45:49 Cernan: That's the soil from on top the rock. And we're taking a piece of the rock itself, which looks pretty much like the other one, Bob. It might be a little bit more vesicular.

146:46:00 Parker: Okay, and that'll be in 466, right?

146:46:06 Cernan: You're right again. Here we are and I'll be able to grab it with my hand. If I put this away. (Pause) Okay. 146:46:23 Schmitt: Okay, the soil came from a half a meter in from the soil boundary....

2) Crew: Logging photography frame counts and planning usage

146:53:16 Parker: And how about a frame callout before you get back on, guys.

146:53:19 Cernan: Got it.

146:53:23 Schmitt: Yeah, I need some new...(Responding to

Bob) Do you want me to get it (a new magazine) here? (Pause)

146:53:33 Cernan: CDR's at fifty.

146:53:34 Parker: Copy that.

146:53:35 Schmitt: A hundred and seventy.

146:53:36 Parker: Copy one seven zero.

146:53:37 Schmitt: LMP's 170.

146:53:41 Parker: And, Jack, it'd be my opinion, since you're just going back over the same path, that you came up this morning, it's probably not necessary.

146:53:49 Schmitt: Okay, I'll use it until it runs out.

146:53:50 Parker: Okay.

3) Crew: Logging rover systems indicators

Presumably all system data would be transmitted by wireless telemetry today.

145:53:39 Cernan: (The gravimeter reading is) 670, 012, 501; $670,012,501$.

146:26:58 Schmitt: Okay. Oh, the (SEP) temperature; they'd like to know. [Jack goes to the SEP receiver behind his seat.] 146:27:06 Schmitt: Temperature is still about 112 .

146:27:08 Parker: Copy that.

As Cernan indicates, it is tedious to be the "voice" of the instruments; notice that he is also interpreting the readings.

146:27:27 Parker: Okay, and, Gene, if you're not off the

Rover, how about the rest of the Rover readouts?

146:27:33 Cernan: Okay, Bob, I'm off, but I'll get them for you. I'm sorry. I look at them, and they all look good to me.

And, you know, I keep forgetting to give them to you.

4) Crew: Asking where materials are located

Notice how Cernan relies on Bob for this information, even though Schmitt is nearby and listening.

145:35:28 Cernan: If I can remember where we put it. Bob, where did we put the small can?

145:35:30 Schmitt: It's in bag 7 under my seat.

Then again within the minute, even though Schmitt showed that he knows where things are stored, Cernan asks CapCom. Evidently, CapCom is very present in Cernan's mind, and serves as an assistant, as if he were on the surface. Schmitt confirms the information, showing that he is attending to the conversation.

146:30:19 Cernan: Say, Bob, where can I get a new set of bags?

146:30:23 Parker: Okay, you want new bags... They'll be under Jack's seat.

146:30:26 Schmitt: Under my seat, there's some, Geno.

146:30:30 Ceman: Okay. Just loose? 
5) Crew: Providing geological descriptions for the record

The only means of recording observations during the EVA is via the voice loop.

146:20:40 Schmitt: Bob, the fragment population - we're at 099/2.0 - is still about the one-percent category of...And it's hard to tell, going into the Sun, what kind of blocks you're dealing with. But my guess is - well, more than a guess - (is that) most of them look like they're slightly vesicular. And, in that regard, resemble the gabbros.

146:21:19 Parker: Okay, copy that....

146:31:47 Schmitt: ... Bob, I have the impression that these blocks are buried up here (and) that the mantle does exist, even on Camelot. There are a few blocks that are lying out on the...(It) looks like they're lying more or less on the surface, but you can attribute those to craters that have disrupted the block field.

146:32:24 Parker: Okay; good observation, Jack.

6) Crew: Providing equipment descriptions

146:41:54 Ceman: You know I've wom the RTV (Room-

Temperature Vulcanizing silicon rubber) off that hammer already.

146:41:57 Schmitt: Yeah, I saw that.

146:42:00 Parker: Roger, 17. Copy that.

7) Crew, CapCom: Suggesting procedures, requesting or

documenting equipment settings and usage

145:34:00 Parker: ... Okay, we're suggesting Intermediate (cooling) for you, Jack.

145:26:04 Parker: And we're going to want the SEP opened and dusted as well here. With the switches turned off....

146:01:15 Schmitt: Hey, Bob, I recommend that, if we ever do this again, let me get off and pick the charge off when we want to deploy it. It really adds to the fatigue of the hands.... 146:06:33 Schmitt: Aah. Stand by on pin 3, gang.

146:06:35 Parker: Copying that. Remember to push it all the way back in, Jack, and start from scratch....

146:00:11 Cernan: Hey, Bob, a note on those (battery) radiators: I have been dusting the covers at every stop, whether that's any help or not.

146:00:19 Parker: Okay; we copy that.

8) CapCom: Indicates elapsed time, time remaining at a site, including walkback (turn around) warnings

145:37:01 Parker: ...we can decide priorities between this station or any other station. It's the fact that we're running up against the walkback constraints here in just a very few minutes, about two-zero (20) minutes...

145:43:45 Parker: ...And, 17, for your thought...We have to be leaving here... Not "like". We have to be leaving here in fourteen minutes. On the move, because of walkback constraints.

Bob interrupts a conversation between the crew to remind them of the priorities, probably because of timing and lack of evidence that they are doing these tasks

146:36:05 Parker: Okay, and a reminder, $17 \ldots$

146:36:07 Schmitt: Gene, if this is what you mean, it's... 146:36:08 Parker: ...you guys, that the primary priority is the blocks and then a rake soil of the white subfloor soil there. And you've only got 15 minutes before we want you driving back to the LM. Over.

146:36:22 Cernan: Okay. We'll get to work. Okay...

Warnings are given at 25, 15, and 10 minutes-again interrupting the crew's conversation.
146:39:57 Parker: Okay, guys...

146:39:58 Schmitt: I'll get a...

146:39:59 Parker: ...looks like you'll be going in about 10 minutes.

9) CapCom: States revised plans for substituting,

skipping, or reprioritizing work

145:24:47 Parker: Okay, and the number 1 and 2 priorities at this station will be samples from the crater rim and the pan from the crater rim. Over.

145:36:14 Parker: 17, Houston. We'd like to get the double core here instead of the small can. Double core, please, instead of the small can.

145:36:23 Cernan: Okay.

145:36:24 Schmitt: Did you want it in the orange?

145:36:26 Parker: Roger. That affirm. We can put cores in gray soil all the time.

CapCom suggests how the crew should overlap and coordinate tasks.

145:44:30 Parker: Why don't you leave the core there Gene, and you can take your stereo pan while Jack's getting that sample. And then you can get together and ram the core home.

CapCom confirms tasks the crew mentions to each other.

146:15:13 Ceman: We're coming up to 103 at 2.6 now, so we need a sample up here.

146:15:17 Schmitt: Okay.

146:15:18 Cernan: Okay. 103, 2.5. Anywhere.

146:15:22 Parker: Roger. That's affirm.

A task request is not a simple statement, but may involve a sequence of confirmations and elaboration-CapCom appears to repeat the request, but notice that the first command he gives Schmitt gives the objective (get the SEP to cool), but not how to do it (turn it off). Five statements are required (including Cernan's repetition) before Schmitt is satisfied.

146:26:28 Parker: As you get off, we'd also like to open the SEP and again get that to cool.

146:26:36 Schmitt: Okay. You wanted to turn it Off?

146:26:39 Parker: That's affirm...

146:26:40 Cernan: Tum it off.

146:26:41 Parker: ...turn it Off, open, dust...

146:26:42 Schmitt: You want it off?

146:26:43 Parker: ...the same thing we've been doing to it all aft(emoon)...(correcting himself) all evening.

146:26:48 Schmitt: Well, it's midday here, Bob. (Pause)

10) Crew, CapCom: Provides navigation advice,

including identifying craters they are seeing

145:57:05 Cernan: Okay, I'm Min. Man, I'll tell you, that

heading is going to put us right...Okay, Bob, give me

a...Dang. Wait a minute.

145:57:15 Parker: The heading you should be generally

taking...

145:57:17 Schmitt: Where we at?

145:57:18 Parker: ...toward Victory is 090, Gene.

145:57:23 Cernan: Okay, can you give me a bearing and range at Victory?

145:57:27 Parker: Okay. Stand by...

145:57:38 Parker: ...105 and 3.1.

With appropriate telemetry, the following is unnecessary.

146:03:03 Cernan: We're at 103, 3.4 .

146:03:06 Parker: Copy that. (Pause)

CapCom provides advice, Jack asks for clarification; Bob defers to their understanding. 
146:17:08 Parker: Copy that. And just press on the same heading you've been carrying there, Gene, and that will get you to Camelot.

146:17:17 Cernan: We want the southwestern edge, huh? 146:17:20 Schmitt: Do you want to go where Station 5 is, Bob (that is, to the planned spot on the southwest rim)? 146:17:23 Parker: That's my understanding, Jack. So press on towards there unless I tell you otherwise.

146:17:29 Schmitt: Well, but you were talking about changing Station 5. I think Station 5 is a pretty good spot (as is).

146:17:34 Parker: Roger. And I think that's where we want to go. I'm just trying to verify that. You can go in that direction, though. I'll get with you if it's not.

146:17:42 Schmitt: Okay. (Pause) It's probably the most concentrated boulder field on Camelot.

146:17:48 Parker: Okay. You know where it is, and we think it's about 092 and 1.6 .

146:17:56 Cernan: 092 and 1.6. You know this country...

146:18:00 Parker: Roger. But you know where it is, so you'll find it when you get there.

\section{Complicating Aspects of Crew-CapCom Work}

The categories of information exchanged and work management suggest an initial design for an automated CapCom "agent." However, the transcript reveals several complications in the verbal exchange and in tracking and planning the work.

1) The crew sometimes mishears or does not listen to each other and CapCom, or misunderstands who is speaking to whom

Another person in mission control (Fendell) is controlling the position of the rover's television camera. Cernan speaks to him about a pan, which Schmitt misunderstands as referring to himself.

145:28:50 Cernan: Well, I'm going to clean their glasses so they know we're (not crazy)...(To Fendell) Can you wait a minute on that pan you're taking?

[Gene moves the TV so that he can dust it.]

145:28:56 Schmitt: I already took it.

145:28:57 Cernan: No, I mean the television camera. (To

Fendell) I'll put you back where I had you.

2) Lack of immediate response to request for advice

suggests communication breakdown

146:50:03 Cernan: ... When do you want us to leave, Bob?

(No answer; pause)

146:50:20 Cernan: Jack, do you read me?

146:50:21 Schmitt: Yeah. (Pause) Hello, Houston.

146:50:24 Parker: Hello, 17. Loud and clear. We'd like you to leave immediately, if not sooner.

3) Dialog is mixed-initiative with interleaved topics

Here CapCom makes a new request, while Cernan and Schmitt respond in turn to two different tasks they are doing. 145:54:03 Parker: And what's your frame count, Jack?

145:54:05 Cernan: Charge number 1.

145:54:07 Schmitt: Okay, (SEP) power's On, recorder's On, the temperature is one-twelve (112).

145:54:16 Parker: I copy that.

4) CapCom loses track of what the crew is doing

The TV image often shows only one crew member; here the TV was off.
145:54:38 Parker: And, Jack, what's your frame count, please? 145:54:42 Schmitt: Wait, Bob, I can give you that on the Rover. [TV off]

145:54:45 Parker: Okay. I thought you were on there.

5) CapCom's remarks were sometimes disruptive and unnecessary

145:55:45 Cernan: That's all right. We got a flag on the Rover, and I'm reading 136 on battery number 2 .

145:55:54 Parker: Say again on that one, Gene.

[Schmitt - "My first inclination in the MOCR would have

been to turn around and say 'Did anybody get that?,' rather than call right up and distract the crew."]

6) Under time pressure, decisions need to be made about competing goals

145:49:34 Cernan: I got to take a couple of more pictures at that contact slope over there. You can't see it from where you are, Jack, but I guess we got to leave. Otherwise it would be nice to sample that dark stuff up on top.

145:49:45 Parker: We need you guys rolling in 7 minutes.

7) Mission control sometimes made scheduling decisions

that were non-optimal based on opportunities visible to the EVA crew

145:56:21 Parker: Roger. You're moving exactly 37 seconds early.

145:56:28 Cernan: Early!? I could have gotten that dark

mantle on the other side of that crater. That's all it would have taken me.

8) CapCom's decisions were based on interactions with other people; these conversations are not transcribed

145:32:21 Schmitt: Hey, you want any of this bagged in the can, Bob? Canned in the bag...or whatever it is?

145:32:30 Parker: Stand by. They're debating that right now.

9) The crew works independently and must periodically ascertain each other's status and provide advice to each other

146:34:52 Schmitt: (Turming toward the Rover) How you coming, Geno?

146:34:53 Cernan: Oh, I've got new bags. I've got new mags.

I've got everything cleaned up and Mark, gravimeter.

146:35:00 Parker: Copy. Mark that.

10) The crew confuses LM location (checklist) with SEP

transmitter (Rover indicator)

146:55:56 Schmitt: It must be pretty close.

146:55:59 Cernan: You bet your life! (Obviously pleased with himself) I'm reading $085 / 1.4$, and that's what my checklist said.

146:56:03 Parker: Roger. (Pause)

[Again, Gene is misreading his checklist.]

11) Photographs may be deficient; quick feedback would help

145:39:26 Cernan: Take your picture.

[This photo, like the others Jack has taken since finishing his pan, is badly overexposed.]

\section{Agent and Robot Technologies to Assist Field Science}

Analysis of the transcript suggests four technologies for dramatically improving surface exploration efficiency, aspects of which we are currently implementing and testing in the Mobile Agents Project [1]:

1) Telemetry between rover and mission support, e.g., rover battery temperature, film frame numbers, bag numbers. Many verbal interactions between the crew and CapCom 
involve reading information that could be automatically provided by telemetry. Bag numbers might be transmitted by a scanning device on the rover or the suit sleeve.

2) $A$ "remote agent," resembling Bob, with whom the crew may have a mixed-initiative dialog about their work, while coordinating this work with a remote crew (at the $\mathrm{Hab}$ or Libration Point) and with Earth. During Apollo 17, Bob plays a distinct role, not like a third member of the EVA crew, but as a remote advisor for recording information, helping find and use equipment, and especially to prioritize and time activities. Although it may be tempting to refer to Bob as a member of the EVA team, the crew relates to him very differently from the way they interact with each other. In many respects, Bob is more present to each of them individually than they are to each other. That is, they individually coordinate their actions and narrations more closely with Bob than they do with each other.

3) A navigation-task display with a map overlaid, indicating the current location, the route so far, and the planned route with stops. Timings indicate how much time was spent at previous stops, projected stop times (adjusted for current performance and schedule changes), and time remaining. The display indicates the current activity and time allocation, plus the next activity.

4) Bag holder and logger-the astronauts spend a lot of time holding a bag open while the other shovels in soil or inserts a rock, or simply carrying sample bags:

146:43:02 Schmitt: Yep. Whew. I've got to have Gene with me since (I) can't carry sample bags.

146:43:09 Parker: Roger.

146:43:10 Schmitt: I probably can if I'm careful; but I keep dropping them..

Having a robot assistant would free up the other crew member. The robot could also automatically scan the bag number, so it needn't be read out loud by the astronaut. This is a classic example of how examining work practice reveals needs that "technology push" would not consider. Assisting the crew in routine tasks should be considered before "autonomous robots" or doing infrequent big jobs, such as unrolling cables.

As indicated in the previous section, the most demanding aspects of this system are understanding natural dialogue, especially interleaved conversations-between the astronauts and each with CapCom-and tracking what the crew is doing.

\section{COLLABORATION IN FIELD SCIENCE ON DEVON ISLAND}

By design, the work of equipment deployment and exploration of the lunar surface was carried out by the two astronauts working independently. Ironically, the most common reason for working together that we find in the Apollo 17 transcript is holding a sample bag open for the other person to shovel in soil-a task a robot could do especially well. Consequently, although the transcripts reveal a great deal about collaboration between CapCom and the crew, the record does not tell us very much about how two scientist-astronauts might collaborate. In fact, Gene Cernan was not a scientist (though he often demonstrated his capability and emphasized he was not Schmitt's assistant), and Jack Schmitt was the only professional geologist to walk on the moon.

To learn about scientists' collaboration, I studied geologists and biologists working at Haughton Crater in the High Canadian Arctic during four field seasons [11]. As the methods have been previously published in detail, I will focus here on analysis of two interactions as a case study. My interest is to consider what would happen if two scientists were working on Mars: If given time to explore (unlike on Apollo), according to their personal interests, how might they interact? How could an agent software system help? What additional services could a robot provide? As before, my fundamental question is to understand what collaboration looks like, and to distinguish it from assistance.

The first interaction is a case of two biologists working together in a boat in Lake Polygon at Haughton Crater, where they discover something worth sampling on the lake bottom (about a foot deep). The second interaction involves one of these biologists working over an hour with a geologist on a ridge, gathering samples.

\section{A. Biologist assisting a biologist}

In this interaction, $\mathrm{C}$ (a biologist) is leaning over the boat, examining the bottom of the lake. $\mathrm{D}$ (another biologist) is paddling the boat, providing assistance. Indentation indicates remarks that overlap. The second column provides an interpretation of D's remarks.

C Need a bag... did we bring extra sample bags?

$D$ suggests how to store sample and points out possible sample.

$\mathrm{D}$ (hands bag) Want to stuff it in that sack?

C Same stuff that's on the shore, actually.

D Here's a large floating piece.

C Okay.... I don't think I need this... it's the same as the shore..algae... (garbled) different...

C (leaning over boat) What's all this small stuff?

$D$ makes basic observation.

D It seems to be well mixed in with the bottom.

C It's full of eggs!

D Really?

C Well, I don't know what they are... yeah,

look...they're green eggs! Are those eggs or are they algae? Nodules of algae...

D It's a...

C ...it's algae...

$D$ agrees with $C$ 's description.

D ...it's algae

C Yeah, I just split one.

D Yup (laughs)... I should say...

C What are they? ...It's a green matrix... grab some of this.

D Yup.

C It's like a mixture of breccia and..

$D$ repeats $C$ 's description and advises about sample.

$D$.... and algae nodules.

$C$ And algae nodules

D Did you get a good hand...

C This is Nostoc isn't it? That forms these green nodules. Ah, Cynobacteria. These are...these are Nostoc nodules. I don't understand what the rest of this is, it's a really weird...matrix of ah... algae and...broken up breccia. Pretty interesting. Do you have another plastic bag here? 
D suggests how to store sample.

D Ah, no, why don't you put it in one of the vials?

$C$ This is just leak... I just stepped on the top accidentally (laughs). Ah, I could use this one, I guess. I want to get a whole clump of this. I don't know whether to put some in one of these bottles actually.

$D$ offers to hold boat steady to facilitate sampling.

DWell, I could hold us right here, we're right over -a whole bed of it

C Should I...I wanted to fill this with water from here, this has got preservative on them... If I throw this in it will be too concentrated...

$D$ (unclear advice)

C Well, I'm wondering about filling this, full of this water, and dumping a whole pile of this in...

DOh for pres..

C ...to preserve it

$D$ asks about method.

D It's a... you're making like a formalin solution?

$C \cdot Y e s$, it's formalin gluteraldehyde, the bottom layer. I'm sending this up to [person].... And then we need a pure water sample as well.... These nodules will be interesting. Because the thing is the whole lake is covered in this. Once we have this id'ed...

$\mathrm{D}$ acknowledges sampling strategy.

\section{Right.}

C It's pretty much the biology of this lake, characterized....

Throughout, it can be seen that $C$ is leading the work process and $\mathrm{D}$ is assisting. His remarks indicate that he is generally familiar with what $C$ is doing, but clearly $C$ dominates in sampling, describing, and planning the work. $\mathrm{C}$ and $\mathrm{D}$ are not collaborating because $\mathrm{D}$ does not have a project of his own here. He is simply assisting $\mathrm{C}$ : He helps find ways to storc the sample, he points out possible material to sample, he makes a simple observation about the materials, and he holds the boat steady. Nevertheless, D is a highly educated assistant, for he makes confirming descriptions ("and algae nodules") that appropriately choose from and repeat C's descriptions. Aside from paddling the boat, $\mathrm{D}$ contributes nothing in this particular interaction that $C$ could not have done himself. Indeed, $D$ is at Lake Polygon primarily for safety and to make C's work easier; the analysis at this site is not D's particular research interest. This is not a collaboration specifically because $D$ is not engaged in personal work at this time. The subsequent analysis of $\mathrm{C}$ working with a geologist shows a very different kind of interaction.

\section{B. Geologist collaborating with a biologist}

The following interaction occurs on the ridge of Lake Sapphire in the Haughton Crater around mid-day on July 18, 1999. C, the same biologist from Lake Polygon, is following $Z$, a geologist. They pick up rocks, hit them with a hammer, and examine surfaces. Numbers indicate local time; comments are in italics. $\mathrm{C}$ is wearing the wireless microphone, so $\mathrm{Z}$ 's remarks are sometimes unclear. Video is recorded from distances varying from close-up to tens of meters.

$C$ indicates to $Z$ what interests him and names it; $Z$ confirms where they are looking; $C$ indicates why it's significant to him.

C Heh, it has got a layer of green in it. Whoa...Check this out (walks over to $Z$ )... See that layer of green?
Z Yup.

C It's an endolith.. [11:54]

$Z \quad$...just below the crust...

C ...a limestone endolith... that's cool... (pointing

for me) it's just in there... a layer of green

$C$ 's first thought is to ask $Z$ to assist, but he thinks better

of $i t$, and opens the rock himself.

C Can you smash up more of this stuff; actually I should

borrow your..." (he takes hammer and starts hitting) [11:55]

$C$ asks $Z$ to confirm the type of rock

C Wow...(hits and opens and looks inside) yeah, there's some more in here as well....it's really excellent.... This is

limestone? [11:56]

$Z$ Yes, dolomitic limestone.

C Cool. (hits more and looks).

$Z$ (arranging backpack and putting on)

Notice how $C$ named the rock's biological aspect (endolith) and $Z$ named the geological aspect (dolomitic limestone). They have collaborated in identifying a limestone endolith, which $\mathrm{C}$ clarifies is shock-altered (fractured by the impact of the meteor that created Haughton crater). However, $Z$ is not personally engaged in biological research, he is simply providing a specific identification that assists $C$. In contrast with $\mathrm{D}, \mathrm{Z}$ 's assistance goes beyond the mechanics of sample collection to include an interpretation of the material, which itself is why the sample is interesting and valuable to $C$. The collaborative relation between $\mathrm{C}$ and $\mathrm{Z}$ is revealed as well in how they handle samples and their route, identifying rocks and discussing their origin.

$C$ doesn't presume to use $Z$ as an assistant; he asks if $Z$ minds to carry C's sample.

$Z$ Want a bag? [11:57]

$\mathrm{C}$ Can I put those in your backpack?... Okay... ( $\mathrm{Z}$ holds bag while $C$ stuffs it, then $C$ takes it)... Excellent. (closes bag)...

Then $Z$ asks if $C$ minds about their going in a certain direction.

Z .... I want to carry on just up here...

C Okay... just to the end there?

Z Yup...

$C$ finds this consistent with his work, and provides more information his personal agenda.

$\mathrm{COh}$, I need to get a water sample for Andy, somewhere at the end there; I wouldn't mind seeing what happens at the end of that lake as well. [11:57]

$Z$ Yeah

A few minutes later, $C$ and $Z$ discuss a sample of gneiss:

$\mathrm{C}$ (on knees) $\mathrm{Oh}$, yeah, (hitting rocks and looking) [12:08]

$Z$ (hits rocks just to side of $C$ )

$\mathrm{C}$ Oh, yeah..cool (examining rocks, $Z$ with hammer)... yeah, this is amazing.

$Z$ volunteers basic geologic information, and they discuss

how the endolith may have formed.

$Z$ And this stuff's probably like, well it's at least a billion years old.

$C$ Endoliths in a billion year old impact shocked gneiss-that's cool!

$Z$ (laughs)

$C$ That's really amazing. (More seriously) So, what does the impact event do to the texture of the rock, would it have 
made it any more survivable for these things to live in? I mean does it makes it less porous? Or...

$Z$ It makes it more porous,

$\mathrm{C}$... or more porous?

$Z$.... yeah. So, I mean, this stuff, that would probably weigh, it that was a proper bit of gneiss...

C ... yeah

$Z$...it would be two or three times that weight?

C Really? Okay

Z I mean, you can find some stuff that's really vesiculated... Now $C$ states his hypothesis about the formation of endoliths:

C Because I've been sort of wondering whether there's a case to be made for increased porosity of rocks that is less dense from being melted... ah, as a habitat for...endoliths. [12:09] Correcting $C, Z$ states that the low density is caused by shocking not melting:

$Z$ Yeah, although these haven't been melted... they've been, yeah, but shock meta...

C ...shock...

Z ...metamorphosed, anyway....if they're melted...

$\mathrm{C}$ The thing is of course to find reports of endoliths in unshocked gneiss..."

Z Yeah

C now asks $Z$ to help him find such samples:

$\mathrm{C} A \mathrm{~A}$, if you find unshocked gneiss around the impact site...? $Z$ Yeah

C ... Could we do a comparison?"

$Z$ I've actually got a few samples back...

$C$ Oh really?

$Z$...from the helicopter flight.. but there's a lot less shocked...

$\mathrm{C}$ ...yeah

$Z$ Behind the base there's ah, loads of gneiss clasts, and some of them range from highly shocked to..this is sort of intermediate, to...

C Okay

$Z$...more or less untouched....so you should be able to... $C$ makes a specific request for getting these samples:

$\mathrm{C}$ Uh, do you want to go out sometime and look at them?

$Z$ Yeah

$C$ That would be cool... What I'd like to do is get a range of, I don't know, $\mathrm{N}=10$ (laughs)

Z Yeah

$C$ Maybe an unshocked, intermediate shocked, and very

shocked and look and see if there are endoliths...

$Z$ I've got lots lying by my tent, which is...

$C$ shows sensitivity to $Z$ 's needs for his own personal project:

C Okay, but are they expendable, though?

$Z$ Yeah, ... which I'm not going to take back anyway

$C$ 's awareness that $Z$ is not his assistant is revealed again as $C$ looks for a bag

$\mathrm{C}$ Do you have another bag? I have some right down there...

Actually you need those don't you? For your samples... ( $Z$ looks in his backpack) Let me see if I can find something

else... Could just put these in my pocket... [12:11]

$Z$ Oh yeah, I've got some more, yeah

$C$ But do you have enough, though?

$Z$ Yeah

C For your own needs?

$\mathrm{Z}$ Yeah
C Okay....(packs)... Ohhkaay. (fastens bag) ... probably really good to get the porosity of these things measured...

$C$ reveals another interest, and asks $Z$ to assist:

C It's a good breccia pile... that's another thing I want to find... endoliths in breccia... You want to smash that one? (hands over) [12:24]

$Z$... quite a nice bit.. mostly a big clast by the looks of it.

$C$ Yeah (both are looking at rocks)

$C$ introduces a term, showing he has some geological

knowledge:

C A hydrothermal one? $[12: 25]$

$Z$ Possibly, yeah, or it could just be corroded.

The different interests of $C$ and $Z$ are most obvious when they find a rock that both would like to keep:

$Z$ That's quite a nice bit... If you feel the weight of that... that's gneiss

C Ah, god...

$Z$ And that should, the density of that should normally be around 3 or 4 grams per centimeter cubed.. that should be...

$C$ There's even algae growing around the outside...

$Z \quad$....should be, oh about 70 ... if not heavier...

$C$ (throws rock in hand and chuckles) yeah, yup...

$\mathrm{Z}$ (chuckles)

C It's incredible..

$Z$ now confirms that this is the kind of rock $C$ is looking for-the impact caused voids enabling organisms to grow inside:

$Z$ That's from the impact, so if you see if you get big voids in that then...

C That's a nice one... I'm going to crack that one open when I get back...

But $Z$ has other purposes in mind, and won't let $C$ keep this sample:

$Z$ Actually I wouldn't mind that myself.

C Oh, okay

$Z$ Should be able to find some more out there.

C I only want a photograph.

$Z$ Yeah

C If we crack it open...

$\mathrm{Z}$ Yeah.. like those, probably some more...

$C$ negotiates a sample-gathering plan that will suit his needs:

C Yeah, if you see any gneiss, shocked or unshocks, just break it open.

$Z$ Right

C Ah, we can...

Z I was just saying behind..

C

..behind the base camp..

$\mathrm{Z}$ Behind the base...I was just looking up there two nights ago, and there's loads behind the base.

C So maybe if you have a morning spare or something we could go up there?

$Z$ A couple of hours, yeah

$C$ And crack them open (looking around)

Z Yup, you're probably not going to find much in this limestone

C So you might look for limestone hollows in martian racks... [12:33]

\section{Comparison of collaboration}

In contrast with $C$ and $D$ in the boat, with $C$ and $Z$ have two distinct interwoven research studies, with an immediate 
common method of gathering samples by wandering, hitting open rocks, and examining what they find. Clearly, $\mathrm{C}$ is relying on $Z$ 's expertise, but not vice versa (indeed, C's publication of this work [12] includes $Z$ as a co-author, but not vice versa [13]). $C$ uses $Z$ as an assistant in asking him to identify rocks, asking for an explanation of their origin, and sometimes asking him to open rocks. However, he is sensitive to not require too much, and indeed shows considerable deference when he checks three times ("for your own needs?") before asking $Z$ to carry his samples. In the most glaring exchange, $Z$ refuses to let $C$ keep a rock, proving that the rocks have different interpretations for the two disciplines, and that he is carrying out his own personal investigation. The two scientists show sensitivity to each other's needs and purposes and try to be helpful. This is most clear for $C$ when he allows $Z$ to lead the way throughout the forty minutes analyzed here.

In short, $Z$ is not C's assistant, but he is clearly helping him. They are collaborating in describing and finding rocks of interest to $C$. But they are not collaborating in accomplishing $Z$ 's work. $Z$ is mostly silent about what he is doing and never makes a summary statement like C's remarks about Mars and martian rocks. $Z$ is perhaps more interested in his particular dissertation study of the crater, but he never mentions his topic or approach. He only once independently takes a rock to $\mathrm{C}$, to show what interests him. As $\mathrm{Z}$ works nearby, he remains available to $C$, but never proactively finds rocks that $\mathrm{C}$ might find of interest. Thus, his contribution is passive, as $\mathrm{C}$ makes requests $\mathrm{Z}$ responds and tries to be helpful.

This lack of symmetry-C is neither an assistant nor a collaborator on Z's project-shows that work interactions can be quite complex, and that people are sensitive to not impose their needs on others. Saying that $C$ and $Z$ are "teammates" would not begin to describe their relation, and would indeed blur over the kinds of demands they may make on each other. They do not share a specific research goal, but engage in a common activity of walking together, identifying rocks, and discussing morphogenesis. C repeats every few moments what he is trying to do, to frame their interaction and perhaps express his recognition of $Z$ 's involvement in C's investigation. Put another way, their individual actions are coordinated, as $\mathrm{C}$ allows $\mathrm{Z}$ to wander, and $\mathrm{Z}$ provides geological interpretations, while offering to help him later to find the additional samples he requires.

What technology would be helpful here? Based on this exchange and many others, our first approach is not to build a "robot collaborator," but simply an voice-commanded agent system, as suggested by the Apollo 17 EVA analysis. As mentioned before, we are developing a multiagent communication system [1] in which software runs in backpacks worn by scientist-astronauts, with wireless transmission of requests and data to their rovers (ATVs), and back to the camp (habitat). The crew interacts using restricted natural language commands, which allow naming places, identifying which sample bags are being used, and describing samples or places. The system automatically tracks the crew's route, noting the location and time of sampling and annotations. Notice that $C$ and $Z$ do not provide this assistance for each other; the computer system will provide a new tool. From the analysis of the transcripts given here, we could imagine another tool by which the recorded conversations of the scientists could be automatically associated with the sample records. For example, the transcripts indicate that the two minutes of conversation before and after a sample is taken could be useful to remind the scientists of the context and their early interpretations.

Table 1: Comparison of robot and software agents to collaborating people during field science

\begin{tabular}{|c|c|c|c|}
\hline & Robot & $\begin{array}{c}\text { Software } \\
\text { Agent }\end{array}$ & Collaborator \\
\hline Sensors & Yes & Yes & Yes \\
\hline Effectors & Yes & No & Yes \\
\hline $\begin{array}{c}\text { Assistance } \\
\text { Emphasized }\end{array}$ & $\begin{array}{c}\text { Physical } \\
\text { coordination }\end{array}$ & $\begin{array}{c}\text { Logging } \\
\text { and } \\
\text { monitoring }\end{array}$ & $\begin{array}{c}\text { Identification, } \\
\text { interpretation, } \\
\text { causal } \\
\text { explanation }\end{array}$ \\
\hline
\end{tabular}

Combining the Apollo and Devon Island analyses, and considering the computer tools under development, a contrast can be drawn among people, software agents, and an actual robot (Table 1). This table can serve as a heuristic for relating technology to the work of field scientists: Develop robots for tasks involving physical mobility and coordination (including reconnaissance); develop an agent system for logging data and monitoring routes, schedules, and resources; and focus advanced research on tools that provide basic information (e.g., "What causes gneiss to form?") that help people relate what they are observing to broad geological and biological theories.

\section{Personal PRojects: The Nature of Conscious IDENTITY AND PURPOSE}

In describing $C$ and $Z$ 's work, we find a better fit in the language of activity and coordinated action; not the language of goals, problem solving, and tasks. Most fundamentally, exploration is not a problem to be solved, but a more general inquiry, within which problems may emerge (such as identifying a rock and its origin). Exploration is an activity, and it is within this activity that $\mathrm{C}$ and $\mathrm{Z}$ are coordinating their actions [4]. This is always most obvious in realizing what did not happen: $Z$ did not wander off ignoring $C$, and $C$ always returned to where $Z$ was hitting rocks. When $Z$ wanted to head in another direction, he checked with $C$ about the destination to be sure it was compatible with his interests. Just because two people are working together in one place, we must be careful to not fall into cliches of describing them as sharing something or even collaborating. $\mathrm{C}$ and $\mathrm{Z}$ are not a team, but two people working on personal projects interwoven in time and place. Even "collaboration" is too coarse to express their relations as a route manager/geology tutor and a biologist studying endoliths in impact-shocked rock. $Z$ did not publish his work with $C$, and they are not co-authors of my article. The three of us were simply working together on different, personal projects on that ridge for several hours at mid-day, July 18, 1999. Our actions were coordinated and cooperative, but we were not working on a single, joint research project (see [14] for similar analysis).

In this section, I elaborate the philosophical analysis, on the point that we can talk about robots or agents coordinating an activity with people and among themselves, but never (yet) 
describe them as collaborating. I suggest that collaboration is a special kind of activity involving different, personal perspectives. In particular, a person can collaborate with another person because of being able to conceive of each other as being conscious beings with their own interests and needs [15], [16]. That is, a joint activity, a collaboration, requires having both something to contribute (a personal perspective), plus being able to show sensitivity to the other person's perspective (empathy). Today's machines are incapable of having either a personal perspective or empathy because they are incapable of conceptualization at all, let alone conceiving the idea of another agent's consciousness.

\section{A. Talking about intelligence}

As Winograd and Flores [17] argued so fervently, the term intelligent refers to qualities of people that no computer program has yet demonstrated. To use the term to refer to current programs (or its equivalent "expert systems") is to confuse the goal of AI with the reality, and thus to lose sight of the standard-human intelligence-that remains to be understood in nature and replicated in machines. Furthermore, the term knowledge has been confused with representations, so again the subject of study-human knowledge-is confused by applying it to artifacts and models (in this respect, confusing the territory and its map [18]). When we consider that William James made similar points in the $19^{\text {th }}$ century about the term memory (mere repetition, such as striking the hour at the same time every day, does not mean the clock remembers what to do), we see how the misapplication of ordinary words has hindered psychological research throughout its history.

Talk about computers being collaborators of people makes the same mistake. Such phrases once again characterize nonhuman systems by qualities that only people have evidenced. This critique is influenced by British "ordinary language" philosophy, especially the writing of Ryle on the concept "mind." He taught us that we must beware using ordinary words to make technical distinctions about mental phenomena:

Many people can talk sense with concepts but cannot talk sense about them; they know by practice how to operate with concepts, anyhow inside familiar fields, but they cannot state the logical regulations governing their use. They are like people who know their way about their own parish, but cannot construct or read a map of it, much less a map of the region or continent in which their parish lies.[19]

Any science based on pretend meanings or projected properties (intelligence, knowledge, memory, collaboration) is at best wishful thinking and at worse hopelessly lost in a sea of imprecision.

\section{B. Talk about Collaborators}

What capabilities would computer systems require to be collaborators? Consider for example research collaborators, scientists who engage in a joint project. Like $Z$ working with $\mathrm{C}$ on Devon Island, these people bring additional research capabilities to an effort. They may be specialized in using a particular instrument, or doing a particular kind of analysis. In defining joint research, collaborators often negotiate goals--who will do what, how capabilities and efforts will leverage off of one another. They enter into a (usually informal) contract, or may write a research proposal to define roles and responsibilities. During this work, collaborators sustain other commitments and participation.

Collaborators on our projects, whether in business or research, are valuable often because they retain membership in communities to which we do not belong. They provide a voice for other interests, which together we may meld into a new perspective, a new way of doing business, a new theory or product. Collaborators may review the joint work and instruct us on other perspectives. This relation is usually, but not necessarily symmetric. A collaborator may be just a consultant or an advisor, as $Z$ is for $C$. Each person handles different parts of the work, according to capability and interest. When collaboration is symmetric, they work independently, without supervision, in handling tasks.

I claim that the general schema of collaboration that I have described has essential elements distinguishing it from other forms of task management. In particular, people may be delegated tasks without being collaborators and they may work independently. These people are often called assistants. Collaborative work must be joint, not merely delegated and piecewise assembled. Because of the interests and intelligent capabilities of professional participants, successful collaboration requires negotiation of objectives, methods, roles, and schedules. Collaborating scientists must negotiate because it is assumed that they retain their individual interests and that their contributions will serve multiple, personal purposes.

In this respect, the person who restocks grocery shelves, although required to be cooperative, is not usually collaborating with the store owner, insofar as he does not participate in the strategy for buying certain goods and displaying them. (Restocking shelves serves only the interests of the store owner, not the person doing the restocking; the owner may enter into a promotional collaboration with vendors.) Nor are housecleaners collaborating with owners in managing a house. Underlings, hired help, and servants are not collaborators. Most laboratory assistants, including novice graduate students, are not collaborators. Other professionals may be hired to handle specialized work, and they are not collaborators either: Travel agents and physicians, for example, work for us, but we do not collaborate. I am not capable of collaborating with a physician because we cannot negotiate and symmetrically manage the work. Most professional-client relations are asymmetric: The client specifies needs or problems, the specialist resolves them. Also, we should not confuse negotiation about what work is desired (e.g., giving instructions to a gardener) as collaboration. A collaboration involves a melding of efforts, not merely a negotiating of requirements. Of course, some professional work, such as designing a house, may become a collaboration if the owner is capable of making detailed design proposals. Then one is not merely indicating desired qualities of the solution, but providing parts and merging them with the other person's work. This is what we mean by collaborative work-the work is joint, not merely assigned, decomposed, or coordinated.

Similarly, involving patients in medical programs by better explaining the methods, risks, and benefits of treatment is allowing them to make better decisions. Understanding what 
medical professionals are doing is a prerequisite for specialists to work jointly, but mere understanding does not make patients into collaborators with their physicians. Patients engaging in medical studies by carrying out treatment programs at home are assisting the professionals, they are not collaborating in the research. A research chemist, a pharmacist, and a physician may collaborate; but very few patients have the capability to provide an independent contribution to medical research projects.

In these respects I depart from Grosz's [14] analysis of collaboration, in which people driving in a convoy are characterized as collaborating (versus merely interacting). It is sufficient to say that they are coordinating their driving. Or perhaps, given the negotiation involved in where and when to stop, they are cooperating (literally, co-operating).

It might be tempting to imagine that people and robots finding a route together, say when exploring a new area, would be collaborating. But again we must examine closely the nature of the conceptualization involved. Would the computer systems merely supply information and apply models? Providing timely, useful information and calculations is cooperative. But evaluating routes for investigative purposes (beyond safety and efficiency) involves scientific perspectives. I claim this involves a non-verbal, conceptual aspect, tied to long-term personal identity and purpose, which computers cannot (yet) have [20].

\section{Collaboration requires consciousness}

Should we try to develop robots that can be collaborators? In ordinary life we do not choose to have every assistant be a collaborator-indeed large areas of social organization would become intractable if all work were open to joint direction, as in a collaboration. Consider for example the relation of a manager to an administrative assistant. They do not jointly decide what letters to write and what to say. The intermediate results of collaborative work often must be negotiated (interpreted) to form a whole, as in the Z's conversation with $\mathrm{C}$ about the relation of melting and shocking. Scientific collaborators almost inevitably speak for different communities. Collaboration by its very nature leaves open the possibility that in some respects perspectives are incommensurable; people may decide to exploit their proposed contributions independently (as $\mathrm{Z}$ did not make $\mathrm{C}$ a coauthor). Consider how far we are from having a machine that could independently decide to withdraw from a project, to define a separate contribution. And why would we want to create such a machine in the first place?

Here lies the rub: Without consciousness, a robot cannot have a project. Projects are an essential aspect of identity, of the experience of being a person, an entity with a history, with ambition, with creative concerns ([21], see the story of Franco Magnani, "The landscape of his dreams"). Having a project is almost entirely ignored by cognitive studies of expertise [18]. Experts are not just case-oriented problem solvers; they are people with careers, on a development path of some sort, becoming someone, being someone.

Creative people have projects, not merely jobs, tasks, or problems. People conceive of who they are and who they are want to be in terms of the projects they undertake. Examples of projects include paintings, formal gardens, buildings, novels, research proposals of all sorts, and computer systems such as Brahms. The work of inventors, artists, and researchers provides quintessential examples of projects.
Inventions, art, and research projects are part of one's life work, and are always at least tacitly conceived with respect to some overarching meaning of "who I am" and "who I want to be."

Other professionals and ordinary people have projects, too. Real estate developers have housing and office development projects, architects have projects, city managers have land-use projects, and a child with a lemonade stand or a tree house has a project. Homes are often viewed as projects by their owners (and this is why they may form a collaboration with an architect). Hobbies, such as gardening, bookbinding, and photography, involve projects that provide recreation and meaning to life. Astronauts on Mars will be engaged in a project of exploration.

Yet a machine without a sense of self cannot have a project, for it cannot conceive "what $I$ am doing now" [20]. (Goal descriptions in computer models are not functionally equivalent to human conceptualizations of activities [15]-[21].) And because it cannot have a personal project, it cannot have a joint project, and thus it cannot collaborate.

To conclude, we should not talk about robots being collaborators, any more than say they are intelligent or have knowledge-until these are factually true. Articulating this delta carefully - the actual differences between people and machines-and not misapplying everyday words like "shared" and "collaborator," is the very starting point for human-robot research, and what makes our engineering endeavor a science.

\section{CONCLUSION: NEXT STEPS FOR WORK SYSTEM DESIGN}

In this paper I have analyzed transcripts of people working together on the moon and in the Arctic. I have distinguished between physical coordination, cooperative action, and collaboration. I emphasized information processing capabilities a computer tool could provide, which we have prototyped in a multi-agent system [1]. The examples suggest that to develop useful tools for field science (which we can call "assistants"), we should focus on route and schedule monitoring, science data logging, and telemetry.

Applying the same methods, robot developers could document and analyze people working together in their domain of choice. Tracking conversations has been shown to be a good heuristic for understanding the work people do in a complex environment [22], [23]. One can then find categories of displays and model-based representations that will support the work. Some of these tools will be databases with perhaps natural language interfaces; some of these systems will be combined with sensors and proactive model-based processors ("agents"); and yet others will also include effectors and be [26] have focused for several years on physical tasks like deploying a long, heavy cable. This is fine, but in actual field work they found that the mundane task of having the robot carry a relay antenna in line of sight with the habitat was more pressing.

When starting with a complex, perhaps dangerous and resource-scarce environment, such as Mars, related experiences, such as the Apollo traverses, may reveal a variety of easily defined problems that technology can actually help solve. Starting with how the people are interacting with each other can provide startling changes in perspective. If the astronauts on Apollo are rarely working together, does this mean that a robot who is a "true teammate" would be off working alone? 
Or might the entire practice of surface exploration be changed by adding a third person? This question is more quickly answered by analyzing appropriate groups of three people, than by adding a rudimentary computer system to a group of two people. This argues that requirements analysis should be empirical, grounded first and foremost in the study of personal concerns.. By better understanding what people are trying to do, we will formulate many practical ideas for what computer systems can help and how they should behave.

\section{ACKNOWLEDGMENT}

Discussions with Maarten Sierhuis have been valuable for shaping the analysis and design suggestions. I am especially grateful to Pascal Lee, principal investigator of the NASAHaughton-Mars Project on Devon Island for making possible my study of field science. I thank Charlie Cockell, Dale Stokes, and Gordon Osinski for allowing me to study their work and for verifying the transcripts. Charlotte Linde also provided help for organizing the paper. For related research, please see http://bill.clancev.name.

\section{REFERENCES}

[1] W. J. Clancey, M. Sierhuis, C. Kaskiris, and R. van Hoof, "Advantages. of Brahms for specifying and implementing a multiagent human-robotic exploration system," Proceedings of FLAIRS Conference, St Augustine, May 2003, to be published.

[2] J. Greenbaum and M. Kyng, (Eds.), Design at work: Cooperative design of computer systems. Hillsdale, NJ: Lawrence Erlbaum Associates, 1991.

[3] D. Norman, The Invisible Computer. Cambridge: The MIT Press. 1998.

[4] W. J. Clancey, "Simulating activities: Relating motives, deliberation and attentive coordination," Cognitive Systems Research 3(3), pp. 471499, September 2002.

[5] W. J. Clancey, P. Sachs, M. Sierhuis, and R. van Hoof, "Brahms: Simulating practice for work systems design," International Journal of Human-Computer Studies, 49, pp. 831-865, 1998.

[6] M. Sierhuis, "Modeling and simulating work practice," Ph.D. thesis, Social Science and Informatics (SWI), Univ. of Amsterdam, SIKS Dissertation Series No. 2001-10, Amsterdam, The Netherlands, ISBN 90-6464-849-2, 2001

[7] A. Acquisti, M. Sierhuis, W. J. Clancey, and J. M. Bradshaw, "Agent Based Modeling of Collaboration and Work Practices Onboard the International Space Station," Proceedings of the IIth ComputerGenerated Forces and Behavior Representation Conference. Orlando, FL, May 7-9, 2002.

[8] E. M. Jones. (1999). Apollo Lunar Surface Journal. [Online]. Available: http// www hq.nasa, gov/alsi/

[9] N. R. Jennings, K. Sycara, and M. Wooldridge, "A roadmap of agent research and development," Autonomous Agents and Multi-Agent Systems, 1, pp. 7-38. 1998.

[10] E. Alonso, E. "AI and agents: state of the art," Al Magazine, 23(3), pp. $25-29,2002$

[11] W. J. Clancey, "Field science ethnography: Methods for systematic observation on an Arctic expedition," Field Methods, 13(3), pp. 223243, August 2001

[12] C. S. Cockell, P. Lee, G. Osinski, G, Horneck, P. Broady, "Impactinduced microbial endolith habitats," Meteoritics and Planetary Science, 37, pp. 1287-1298, 2002.

[13] G. R. Osinski and J. G. Spray, Impact-generated carbonate meits: evidence from the Haughton structure, Canada. Earth and Planetary Science Letters, 194, pp. 17-29, 2001.

[14] B. J. Grosz, "Collaborative systems: AAAI-94 Presidential Address," AI Magazine, Summer, 1996, pp. 67-85

[15] J. Barresi, and C. Moore, Intentional relations and social understanding. Behovioral and Brain Sciences, 19(1), 1996, pp. 107-154.

[16] W. J. Clancey, "Studying the varieties of consciousness: Stories about zombies or the life about us?" Journal of the Learning Sciences, 8 (3 \& 4), 1999, pp. 525-540.
[17] T. Winograd, and F. Flores, Understanding Computers and Cognition: $A$ New Foundation for Design. Norwood: Ablex, 1986.

[18] W. J. Clancey, Situated Cognition: On Human Knowledge and Computer Representations. New York: Cambridge, 1997.

[19] G. Ryle, The Concept of Mind. New York: Barnes \& Noble, 1949, pp. $7-8$

[20] W. J. Clancey, Conceptual Coordination: How the Mind Orders Experience in Time. Mahwah, NJ: Erlbaum, 1999.

[21] O. Sacks, An Anthropologist on Mars: Seven Paradoxical Tales. New York: Knopf, 1995.

[22] C. D. Kukla, E. A. Clemens, R. S. Morse, and D. Cash, "Designing effective systems: A tool approach," in Usability: Turning Technologies into Tools, P.S. Adler and T.A. Winograd, Eds. New York: Oxford University Press, 1992, pp. 41-65.

[23] J. Whalen and Vinkhuyzen, E. "Expert systems in (inter)action: documenting document machine problems over the telephone," in Workplace studies: Recovering work practice and informing system design, P. Luff, J. Hindmarsh, and $\mathrm{C}$. Heath, Eds. Cambridge: Cambridge University Press, 2002.

[24] NASA Exploration Team (NEXT). Space Robotics Technology Report, May 2002.

[25] W. J. Clancey, "A closed Mars analog simulation: The approach of crew 5 at the Mars Desert Research Station," Mars Society Annual Conference, Boulder, August 2002.

[26] K. Shillcutt, R. Burridge, J. Graham, "Boudreaux the Robot (a.k.a. EVA Robotic Assistant)," Papers from the AAAI Fall Symposium on Human-Robot Interaction, Tech Rpt FS-02-03, Falmouth, MA, 2002, pp. 92-96.

\section{$<<$ photo goes here $>>$}

William J. Clancey has degrees in mathematical sciences (BA, Rice University, Houston, TX, 1974) and computer science (PhD, Stanford University, Stanford, CA, 1979).

$\mathrm{He}$ is a Senior Research Scientist in the Institute for Human and Machine Cognition at the University of West Florida, Pensacola, FL. He holds a joint position at the NASA-Ames Research Center, Computational Sciences Division, where he is Chief Scientist for Human-Centered Computing. His recent books examine the relation of descriptive cognitive models to human experience and neural processes: Situated Cognition: On Human knowledge and computer representations (New York: Cambridge,1997), and Conceptual Coordination: How the mind orders experience in time (Mahwah, NJ, 1999). Prior to joining IHMC and NASA, Clancey was a founding member of the Institute for Research on Learning (1987-1997) where he co-developed the work system design methods of business anthropology in corporate environments. At the Knowledge Systems Laboratory of Stanford University (1974-1987), Clancey developed some of the earliest artificial intelligence programs for explanation, the critiquing method of consultation, tutorial discourse, and student modeling. His analytic papers in the joumal Artificial Intelligence ("The epistemology of a rulebased expert system" and "Heuristic classification") have been among the most cited. He has presented this research in tutorials and keynote addresses in eighteen countries.

Dr. Clancey is a Fellow of the American Association of Artificial Intelligence, a Fellow of the American College of Medical Informatics, and a member of the steering committee of the Mars Society. He serves as a NASA Visiting Researcher for the Challenger Center's school outreach program. 